\title{
Diagnosis of rubella virus using antigen- conjugated Au@Pt nanorods as nanozyme probe
}

This article was published in the following Dove Press journal:

International Journal of Nanomedicine

\section{Tao Zhang' \\ Fang $\operatorname{Tian}^{2}$ \\ Lin Long' \\ Jianbo Liu $^{3}$ \\ Xiaochun $\mathrm{Wu}^{4}$}

'Department of Clinical Laboratory, Zaozhuang Municipal Center for Disease Control and Prevention, Zaozhuang, China; ${ }^{2}$ Department of Clinical Laboratory, Zaozhuang Municipal Maternal and Child Health Hospital, Zaozhuang, China; ${ }^{3}$ College of Opto-electronic Engineering, Zaozhuang University, Zaozhuang, China; ${ }^{4}$ CAS Key Laboratory of Standardization and Measurement for Nanotechnology, National Center for Nanoscience and Technology, Beijing, China
Correspondence: Jianbo Liu College of Opto-electronic Engineering, Zaozhuang University, No. I Bei'an Road, Zaozhuang 277I60, China

Email linyibm@I63.com

Xiaochun Wu

CAS Key Laboratory of Standardization and Measurement for Nanotechnology, National Center for Nanoscience and

Technology, No. II ZhongGuanCun

BeiYiTiao, Beijing 100190, China

Email wuxc@nanoctr.cn
Background: As nanotechnology advances rapidly, the nanozymes which could replace protein enzymes in bioanalytical assays bring a new opportunity to the development of simple and sensitive diagnostic tools.

Purpose: Antibody-conjugated Au-Pt core/shell nanorods (Au@Pt NRs) have been used for nanozyme probes for diagnosis of rubella virus. Au@Pt NRs, prepared by Au nanorod-mediated growth, exhibit peroxidase-like activities and could serve as an inexpensive replacement for horseradish peroxidase (HRP) in conjugation of antigen.

Method: Using a capture enzyme-linked immunosorbant assay for the determination of rubella virus.

Results: Compared with antibody-conjugated HRP, the antigen-conjugated Au@Pt NRs are more stable and more robust, but less expensive. Based on the enhanced catalytic properties of this nanozyme probe, it was found that the antigen-conjugated Au@Pt NRs-based enzymelinked immunosorbant assay exhibited good sensitivity.

Conclusion: Our results indicate that these antigen-conjugated Au@Pt NRs represent a suitable nanozyme probe for future clinical applications under various conditions.

Keywords: gold nanorods, nanozyme, antigen conjugation, rubella virus, diagnosis

\section{Background}

Rubella virus (RV) is the causative agent of rubella disease or so-called German measles. Although most cases of infection lead to a mild, self-limiting measles-like disease, the real threat arises when RV infects pregnant women, particularly during the first trimester, when it will cause severe fetal anomalies or even fetal loss. ${ }^{1-3}$ For this reason, it is of great practical significance to establish a simple, sensitive detection method for RV. Laboratory confirmation of recently acquired rubella relies commonly on serum detection of RV-specific IgM antibodies. Enzyme-linked immunosorbent assay (ELISA) is an important method for the detection of various proteins in immunologic reactions, finding applications in numerous disciplines including the diagnosis of infectious diseases. ${ }^{4-6}$ Reports have demonstrated the efficiency of detecting rubella-specific IgM or IgG antibodies in human serum or plasma using ELISA techniques in indirect or capture format. ${ }^{7,8}$ However, the most commonly used enzymes in immunoassay which lose their enzymatic activities gradually over long-term storage include horseradish peroxidase (HRP). To overcome these limits, various studies on replacing natural enzymes have been reported. ${ }^{9-12}$ As nanotechnology advances fast, the nanozymes which could replace protein enzymes in bioanalytical assays bring a new opportunity to the development of simple and sensitive diagnostic tools. ${ }^{13-16}$ Nanozymes comprise many types of materials, iron oxide, vanadium oxide, cerium oxide, manganese oxide, gold, platinum, palladium, gold-silver alloys, carbon nanotubes, graphene, metal chalcogenides, and other 


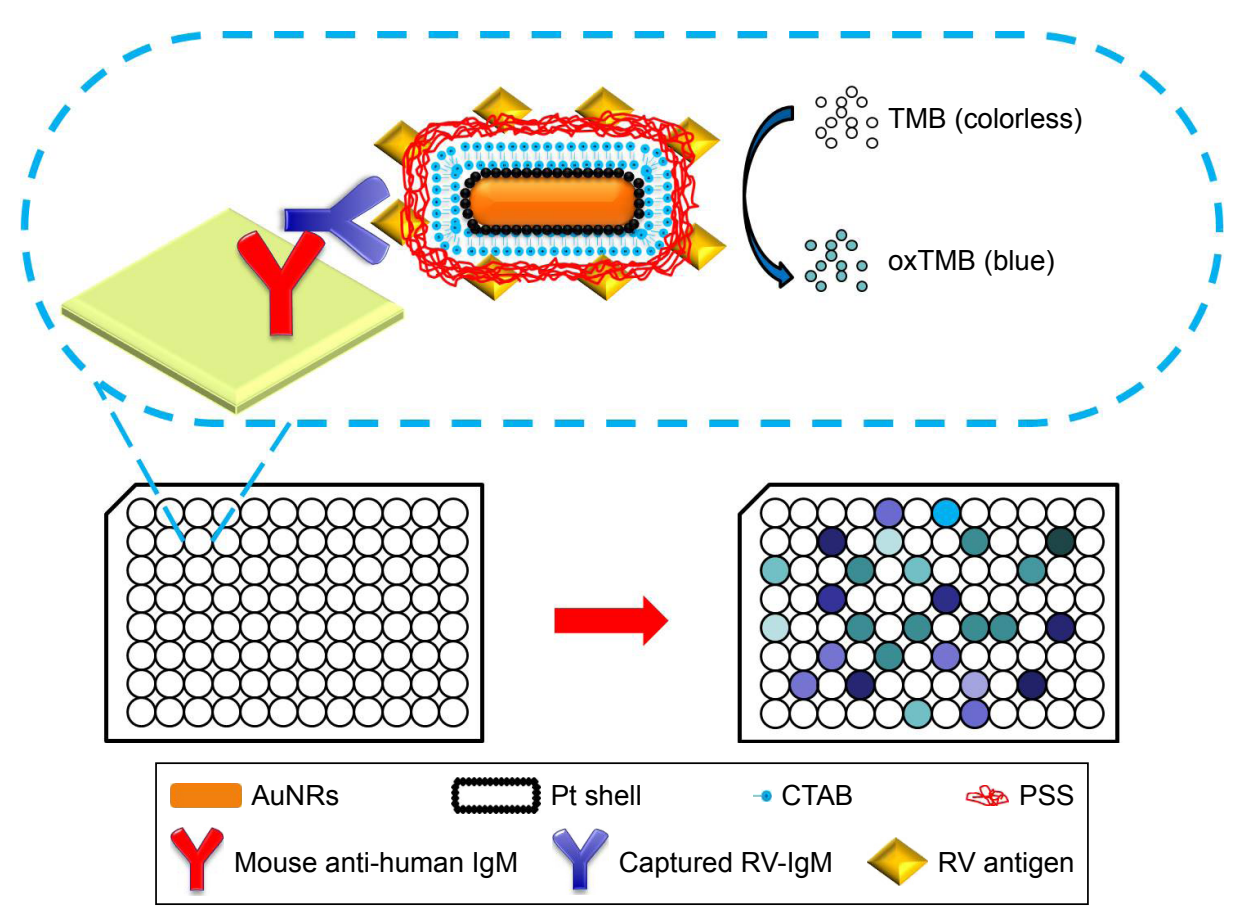

Figure I Schematic representation of antigen-conjugated Au@Pt NRs-based ELISA system.

Abbreviations: ELISA, enzyme-linked immunosorbent assay; CTAB, cetylmethylammonium bromide; NR, nanorod; PSS, poly(sodium-4-styrene sulfonate); TMB, 3,3'5,5'tetramethylbenzidine; $\mathrm{RV}$, rubella virus.

materials. ${ }^{17-26}$ Compared with natural enzymes, nanozymes are advantageous in several aspects, such as low cost, ease of mass production, robustness to harsh environments, high stability, long-term storage, large surface area for further modification and bioconjugation and so on. ${ }^{27-32}$

Previously, we found $\mathrm{Au}-\mathrm{Pt}$ core/shell nanorods (Au@Pt NRs) have intrinsic multiple enzyme mimetic capability, for example, oxidase, peroxidase, and catalase mimetic activity. ${ }^{33-37}$ The as-synthesized Au@Pt NRs are able to catalyze color reactions in immunoassay and, therefore, can be used to replace the enzymes in conventional ELISA. In this work, we designed a novel conjugate based on antigenconjugatedAu@Pt NRs, which was used as nanozyme probe for virus serodiagnosis. We chose Au@Pt NRs based on the following reasons. Small Pt nanoparticles often show high catalytic activity. However, they are also easy to aggregate and a proper support is often needed to keep them in a welldispersed state. Au NRs are chosen as the support for the Pt nanoparticles due to their well-developed synthesis method. Owing to large cohesive energy, Pt exhibits island growth mode on gold surface. Thus, well-dispersed Pt dots can be obtained using Au NRs as a support and the ligand effect can further enhance the catalytic activity of the Au@Pt NRs. For the surface modification method, rubella antigen is generally conjugated on the surface of the nanozyme to provide specificity toward antibody molecules. Significantly, Au@Pt
NRs with high surface areas offer a possibility to design probes for signal amplification. Using the reaction system of 3,3',5,5'-tetramethylbenzidine (TMB) and $\mathrm{H}_{2} \mathrm{O}_{2}$, peroxidaselike activity of antigen-conjugated Au@Pt NRs was investigated. Moreover, compared with antigen-conjugated HRP, antigen-conjugated $\mathrm{Au} @ \mathrm{Pt}$ NRs are more stable and possess an almost unchanged catalytic activity over a wide range of temperatures and $\mathrm{pH}$. Replacing antigen-conjugated HRP, the functionalized nanoprobes were employed to capture ELISA and realized highly sensitive detection (Figure 1). Another study was carried out side by side to compare the performance of the antigen-conjugated Au@Pt NRs-based ELISA to traditional HRP-based ELISA. At the same time, the specificity of the antigen-conjugated Au@Pt NRs-based ELISA for RV-positive serum was also investigated by comparing with other infectious virus. As a new kind of nanozyme probe, antigen-conjugated $\mathrm{Au} @$ Pt NRs could be applied in various potential areas of catalysis and nanobiotechnology.

\section{Materials and methods Materials}

Sodium borohydride $\left(\mathrm{NaBH}_{4}\right), \mathrm{CTAB}$, poly(sodium-4-styrene sulfonate) (PSS), chlorauric acid $\left(\mathrm{HAuCl}_{4} \cdot 3 \mathrm{H}_{2} \mathrm{O}\right)$, potassium tetrachloroplatinate(II) $\left(\mathrm{K}_{2} \mathrm{PtCl}_{4}\right)$, silver nitrate $\left(\mathrm{AgNO}_{3}\right)$, L-ascorbic acid (AA), $30 \% \mathrm{H}_{2} \mathrm{O}_{2}$, and TMB were all purchased from Alfa Aesar (Ward Hill, MA, USA) and used as received. 
Rubella antigen, mouse anti-human IgM antibodies coated plate, HRP-antigen conjugates, and positive and negative serum samples (ELISA kit) were purchased from Kerunda Bioengineering company (Shenzhen, China). Milli-Q water $(18 \mathrm{M} \Omega \mathrm{cm})$ was used for all solution preparations.

\section{Synthesis of gold NRs}

$\mathrm{Au}$ NRs were synthesized using a seed-mediated growth procedure. CTAB-capped Au seeds were synthesized by chemical reduction of $\mathrm{HAuCl}_{4}$ with $\mathrm{NaBH}_{4}$. CTAB $(7.5 \mathrm{~mL}$, $0.1 \mathrm{M})$ was mixed with $\mathrm{HAuCl}_{4}(100 \mu \mathrm{L}, 24 \mathrm{mM})$, diluted with water to $9.4 \mathrm{~mL}$, and stirred with a magnetic stirrer. Then, ice-cold $\mathrm{NaBH}_{4}(0.6 \mathrm{~mL}, 0.01 \mathrm{M})$ was added. The solution color immediately turned from bright yellow to brown, indicating the formation of seeds. The Au seeds were used within 2-5 hours. Then, $120 \mu \mathrm{L}$ seed solution was added to the growth solution consisting of CTAB $(100 \mathrm{~mL}, 0.1 \mathrm{M})$, $\mathrm{HAuCl}_{4}(2.04 \mathrm{~mL}, 24 \mathrm{mM}), \mathrm{AgNO}_{3}(1.05 \mathrm{~mL}, 10 \mathrm{mM})$, $\mathrm{H}_{2} \mathrm{SO}_{4}(2 \mathrm{~mL}, 0.5 \mathrm{M})$, and $\mathrm{AA}(800 \mu \mathrm{L}, 0.1 \mathrm{M})$ to initiate the growth of Au NRs. After 12 hours, the reaction was stopped. The obtained $\mathrm{Au}$ NRs were purified by centrifuging the solution at 12,000 rpm for 5 minutes twice. The precipitate was collected and redispersed in deionized water.

\section{Synthesis of Au@Pt NRs}

Three samples of the purified Au NR solutions ( $1 \mathrm{~mL}$ ) were mixed with $62.5 \mu \mathrm{L}$ of $2 \mathrm{mM} \mathrm{PtCl}_{4}{ }^{2-}$ aqueous solution. Then, $12.5 \mu \mathrm{L}$ of $0.1 \mathrm{M}$ AA was added and the total solution volume was diluted to $2 \mathrm{~mL}$. The mixture was shaken vigorously and then placed in a $30^{\circ} \mathrm{C}$ water bath for 30 minutes. Within several minutes, the color of the solution changed from pink-red to dark gray, suggesting the formation of a $\mathrm{Pt}$ shell. Then, $1 \mathrm{~mL}$ of $0.1 \mathrm{M}$ CTAB was added.

\section{Modification of the Au@Pt NRs with PSS}

CTAB-coated NR solution (1 mL, Au@Pt NRs) was centrifuged at 12,000 rpm for 10 minutes, and the precipitate was dispersed in $0.5 \mathrm{~mL}$ PSS aqueous solution $(2 \mathrm{mg} / \mathrm{mL}$ containing $6 \mathrm{mM} \mathrm{NaCl})$. Then, the solution was stirred magnetically for 3 hours. After that, it was centrifuged at 12,000 rpm for 10 minutes, and the precipitate was redispersed in water.

\section{Preparation of antigen-conjugated Au@Pt NRs}

PSS-coated Au@Pt NR solution (50 $\mu \mathrm{L}, 5$ nM) was first dispersed into $1 \mathrm{~mL}$ PBS buffer (0.1 M, pH 7.4). Then $50 \mu \mathrm{L}$ of $10 \mathrm{mg} / \mathrm{mL}$ rubella antigen was added to the above $\mathrm{Au} @ \mathrm{Pt}$ NRs solution and incubated at $37^{\circ} \mathrm{C}$ for 96 hours. After incubation, the mixture was centrifuged at $12,000 \mathrm{rpm} / \mathrm{min}$ for 5 minutes twice. Then, the precipitate was collected and redispersed in $100 \mu \mathrm{L}$ PBS buffer (0.1 M, pH 7.4). Finally, it was dispersed in PBS buffer ( $\mathrm{pH} 7.4)$ at a concentration of $2.5 \mathrm{nM}$.

\section{Detection of rubella IgM antibodies by ELISA}

Detection of rubella IgM antibodies by ELISA was performed in 96-well polystyrene plates. Each well of the 96-well plates was precoated with mouse anti-human IgM antibodies. Firstly, each well was blocked with 5\% bovine serum albumin (diluted in $\mathrm{PBS}, \mathrm{pH} 7.4$ ) for 1 hour at $37^{\circ} \mathrm{C}$ to avoid the nonspecific interaction with the plate surface. Then, the plates were washed three times with PBS with Tween 20 (PBST) buffer (pH 7.4). After this, $100 \mu \mathrm{L}$ of negative control, positive control, or diluted sample was added to the plate and incubated at $37^{\circ} \mathrm{C}$ for 0.5 hour. The plates were washed three times with PBST buffer ( $\mathrm{pH}$ 7.4) to remove the unbound rubella IgM antibodies. Then, $100 \mu \mathrm{L}$ of $\mathrm{Au} @$ Pt NR-antigen conjugates was added to each well and incubated for 0.5 hour at $37^{\circ} \mathrm{C}$. The plates were washed five times with PBST buffer ( $\mathrm{pH} 7.4)$ to remove the unbound $\mathrm{Au} @ \mathrm{Pt} \mathrm{NR}$-antigen conjugates. The color development was initiated by adding $100 \mu \mathrm{L}$ substrate solution ( $1 \mathrm{mM}$ TMB, $50 \mathrm{mM} \mathrm{H}_{2} \mathrm{O}_{2}$ in PBS buffer, $\mathrm{pH}$ 5) into each well. The reaction was stopped after 10 minutes using $50 \mu \mathrm{L}$ of $2 \mathrm{M} \mathrm{H}_{2} \mathrm{SO}_{4}$. Absorbance was read at $450 \mathrm{~nm}$. The clinical serum samples were selected from patients with clinical signs of rubella infection or from the patients who had been exposed to RV. The clinical serum experiment was checked with positive control, negative control, and the blank. Buffer solution was used as the blank.

\section{Characterizations}

Ultraviolet-visible-near-infrared extinction spectra were obtained from a Varian Cary 50. Transmission electron microscopy was performed on Tecnai G2 T20 S-TWIN (T20). The zeta potential data were obtained from Delsa Nano C (Beckman Coulter, Brea, CA, USA). ELISA was conducted on Infinite ${ }^{\mathrm{TM}}$ M200.

\section{Results and discussion Characterization of Au@Pt NRs and antigen-conjugated Au@Pt NRs}

Herein, using Au NRs as seeds, we prepared Au@Pt nanostructures under mild conditions. Au NRs have an average length of $60 \mathrm{~nm}$ and width of $16 \mathrm{~nm}$, and the aspect ratio (length vs width) of the Au NRs here is 3.8 (Figure 2). Pt nanodots with sizes of 3-4 nm were formed on the Au NRs with 

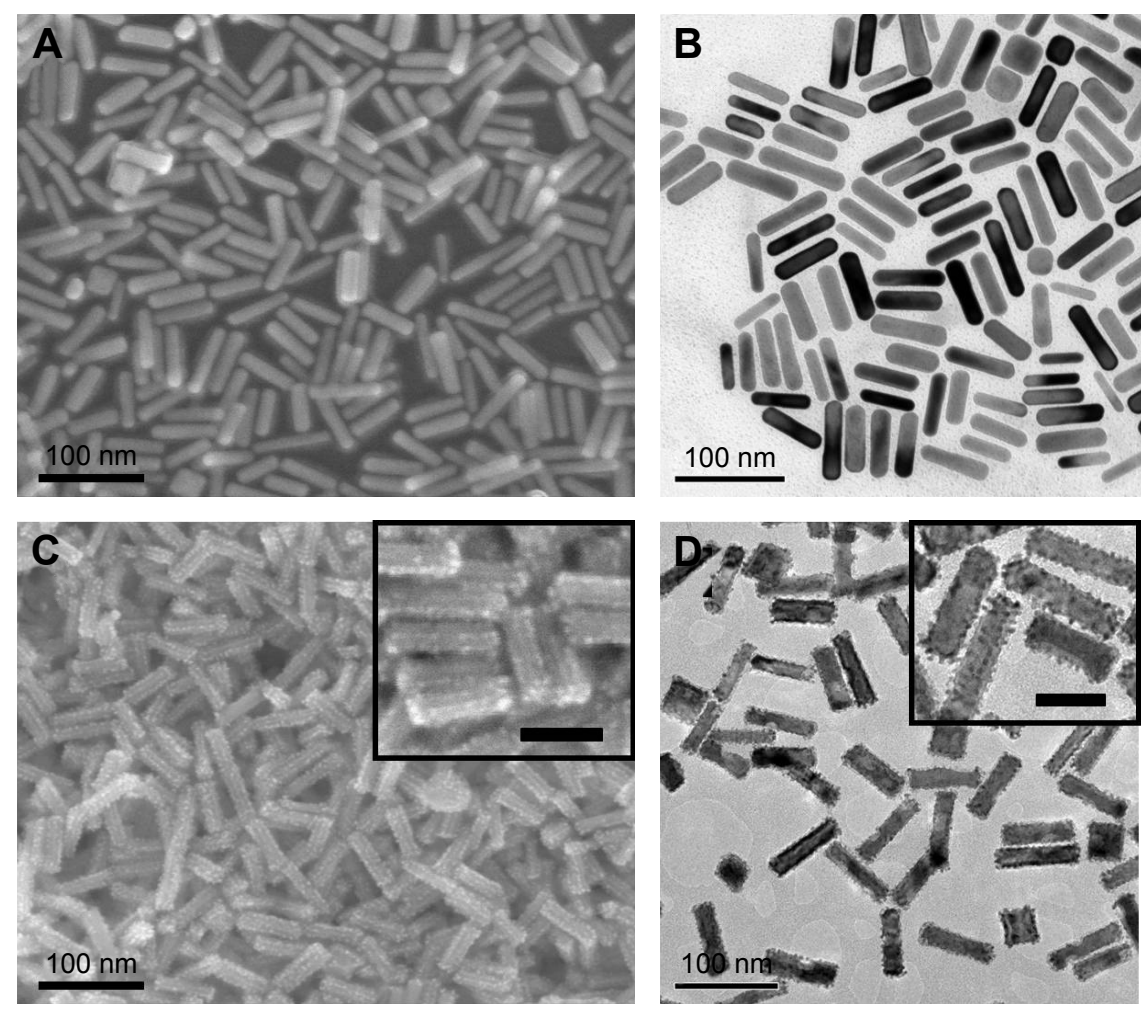

Figure 2 Typical SEM images of (A) Au NRs and (C) Au@Pt NRs. Typical TEM images of (B) Au NRs and (D) Au@Pt NRs. Note: The scale bar of insets in (C) and (D) is $50 \mathrm{~nm}$.

Abbreviations: NR, nanorod; SEM, scanning electron microscopy; TEM, transmission electron microscopy.

a homogeneous distribution, and such a structure is desired for better catalytic activity. As shown in Figure 3, the Au NRs exhibit a strong longitudinal surface plasmonic resonance (SPR) band with a peak at $780 \mathrm{~nm}$. Upon depositing Pt at a Pt/Au ratio of 0.2, Au@Pt NRs exhibit well-defined and
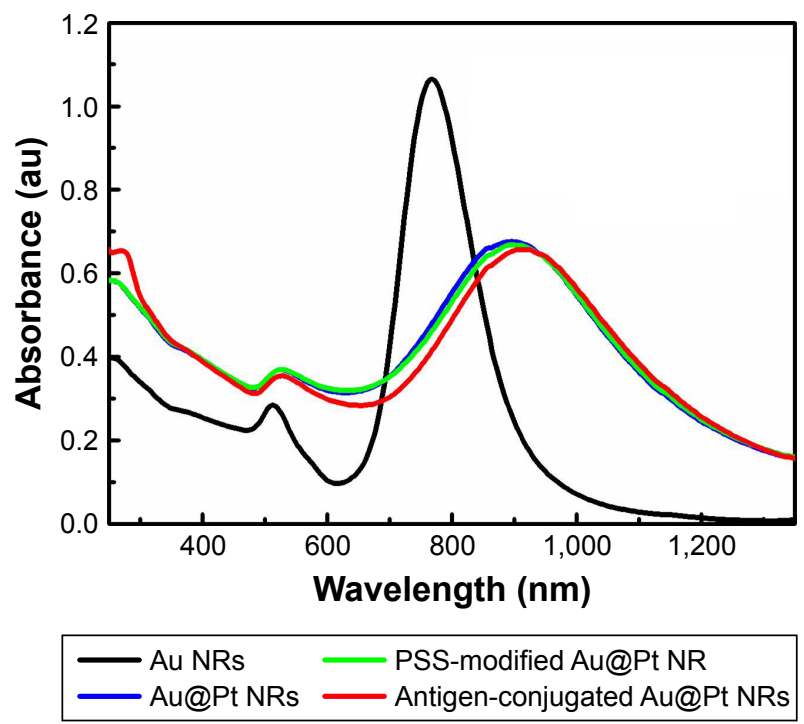

Figure 3 UV-vis-NIR spectra of Au NRs, Au@Pt NRs, PSS-modified Au@Pt NRs, and antigen-conjugated Au@Pt NRs.

Abbreviations: NIR, near infrared; NR, nanorod; PSS, poly(sodium-4-styrene sulfonate); UV, ultraviolet; vis, visible. red-shifted longitudinal SPR bands in the visible and nearinfrared region. For small Pt NPs only have SPR features in the ultraviolet region, which are difficult to employ, using Au NRs as support provides an easy way to characterize the SPR features of Pt. Also, both the amount and thickness of Pt determine its contribution to the final position and strength of the overall SPR features.

Zeta potential is used to predict the surface charge and stability of the nanoparticles. In our case, the as-prepared Au NRs are positively charged because of the presence of a bilayer of cetylmethylammonium bromide (CTAB; Table 1), but it should be changed to negative charge to immobilize specific antigens by electrostatic interactions. CTAB facilitates electrostatic adsorption of an anionic polyelectrolyte, PSS. PSS was coated to CTAB-capped Au@Pt NRs via electrostatic

Table I Effective diameter and zeta potentials of various nanoparticles

\begin{tabular}{lll}
\hline Materials & $\begin{array}{l}\text { Effective } \\
\text { diameter }(\mathbf{n m})\end{array}$ & $\begin{array}{l}\text { Zeta potential } \\
(\mathbf{m V})\end{array}$ \\
\hline Au NRs & $17.5 \pm 1.3$ & $24.2 \pm 1.4$ \\
Au@Pt NRs & $28.1 \pm 0.4$ & $20.1 \pm 0.5$ \\
PSS-modified Au@Pt & $34.2 \pm 0.8$ & $-31.9 \pm 2.1$ \\
Antigen-conjugated Au@Pt NRs & $82.0 \pm 2.1$ & $-19.1 \pm 1.5$ \\
\hline
\end{tabular}

Abbreviations: NR, nanorod; PSS, poly(sodium-4-styrene sulfonate). 
assembly, and it endows the NRs an enhanced stability in a wide $\mathrm{pH}$ range. Besides, the small antigen molecule could be directly conjugated on the surface of nanozyme through electrostatic force. As shown in Figure 3, PSS modification does not lead to obvious change in the SPR features of $\mathrm{Au} @ \mathrm{Pt}$ NRs. Figure 3 also illustrates that conjugating rubella antigen onto the surface of Au@Pt NRs would lead to a slight red shift with slight damping in the intensity of longitudinal SPR features, originating from the longitudinal SPR properties highly sensitive to changes in the dielectric constant of the local environment of Au@Pt NR surfaces. Table 1 shows that surface charges of NRs became less negative, also confirming the successful binding of the molecule to the NRs.

In this study, a light-scattering technique (dynamic light scattering) was used to determine the effective diameter of the nanoparticles (Table 1). It is worth mentioning that the size of the as-prepared Au NRs was $60 \mathrm{~nm}$ in length and $16 \mathrm{~nm}$ in width. However, light scattering typically showed an effective diameter of $17.5 \mathrm{~nm}$. The light-scattering analysis assumes that particles are spherical; hence, due to the rod shape, the diameter obtained from dynamic light scattering measurements is not the actual size of the NRs. The effective diameter is used to evaluate the relative size upon various coatings. Forming a Pt nanodots shell on Au NRs would lead to an increase in the effective diameter. Upon further coating with a layer of PSS, the effective diameter of the Au@Pt NRs would reach 34.2 nm. After antigen conjugation process, the effective diameter of the conjugate becomes $82 \mathrm{~nm}$. Hence, a smooth increase in the effective diameter of the Au NRs observed by light-scattering measurements indicates an increase in the hydrodynamic radius of the particles due to adsorption of different surface modifiers, and not the aggregation of the nanoparticles.

The stability of antigen-conjugated Au@Pt NRs over storage time was evaluated using zeta potential and also

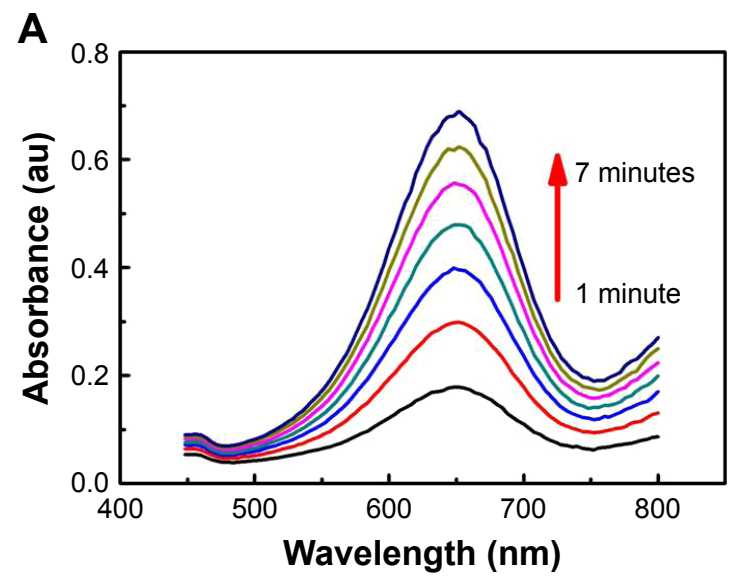

their effective diameter (Figure S1). The antigen-conjugated $\mathrm{Au} @$ Pt NRs exhibited stable average diameter and zeta potential over 4 weeks, further revealing their good stability.

\section{Optimization of catalytic conditions of antigen-conjugated Au@Pt NRs}

Previous studies have proved that the as-prepared Au@Pt indeed exhibited peroxidase-like activity. Therefore, the functionalized nanoprobe, antigen-conjugated Au NRs, would have similar catalytic activity. The color reaction of TMB in the presence of $\mathrm{H}_{2} \mathrm{O}_{2}$ was used to demonstrate the catalytic activity of the antigen-conjugated Au NRs.

As shown in Figure 4A and B, after mixing the antigenconjugated $\mathrm{Au}$ NRs with $\mathrm{TMB}$ and $\mathrm{H}_{2} \mathrm{O}_{2}$, the mixture turned from clear to blue (with a peak at $652 \mathrm{~nm}$ in the absorbance spectra). Compared with antigen-conjugated HRP, antigenconjugated $\mathrm{Au} @$ Pt NRs showed a higher kinetics due to more catalytic sites provided by the larger surface area of the nanoparticles (Figure S2). The color development was stopped by the addition of $\mathrm{H}_{2} \mathrm{SO}_{4}$, changing the color to yellow with a peak at $450 \mathrm{~nm}$ in the absorbance spectra. To achieve an optimal analytical performance of the antigen-conjugated Au NRs, various parameters such as concentration of TMB/ $\mathrm{H}_{2} \mathrm{O}_{2}$, concentration of antigen-conjugated $\mathrm{Au} @ \mathrm{Pt}$ NRs, reaction time, $\mathrm{pH}$, and temperature are optimized (Figure 4). The concentration of TMB is a key factor because it determines the color level of the reaction system. Thus, the influence of the concentration of TMB from 0.1 to $1 \mathrm{mM}$ was investigated. Figure $4 \mathrm{C}$ shows that the activity of antigenconjugated Au@Pt NRs increased up to 0.75 mM TMB, and at higher concentrations, the absorbance of the system reached the plateau of maxima. Only slight changes in light intensity were observed with further increase in concentration of TMB. The $\mathrm{H}_{2} \mathrm{O}_{2}$ concentration also has a very important

B

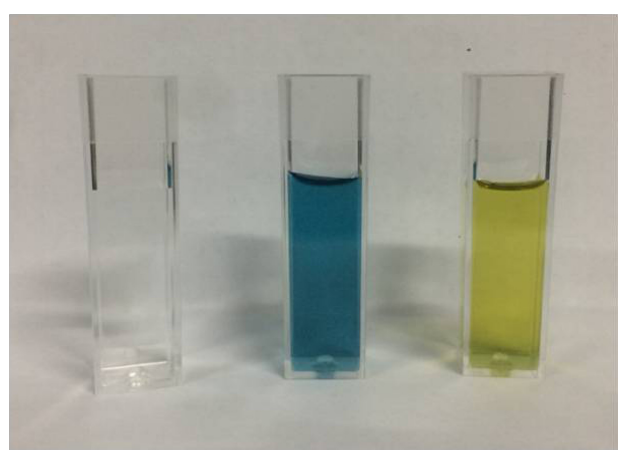

Figure 4 (Continued) 

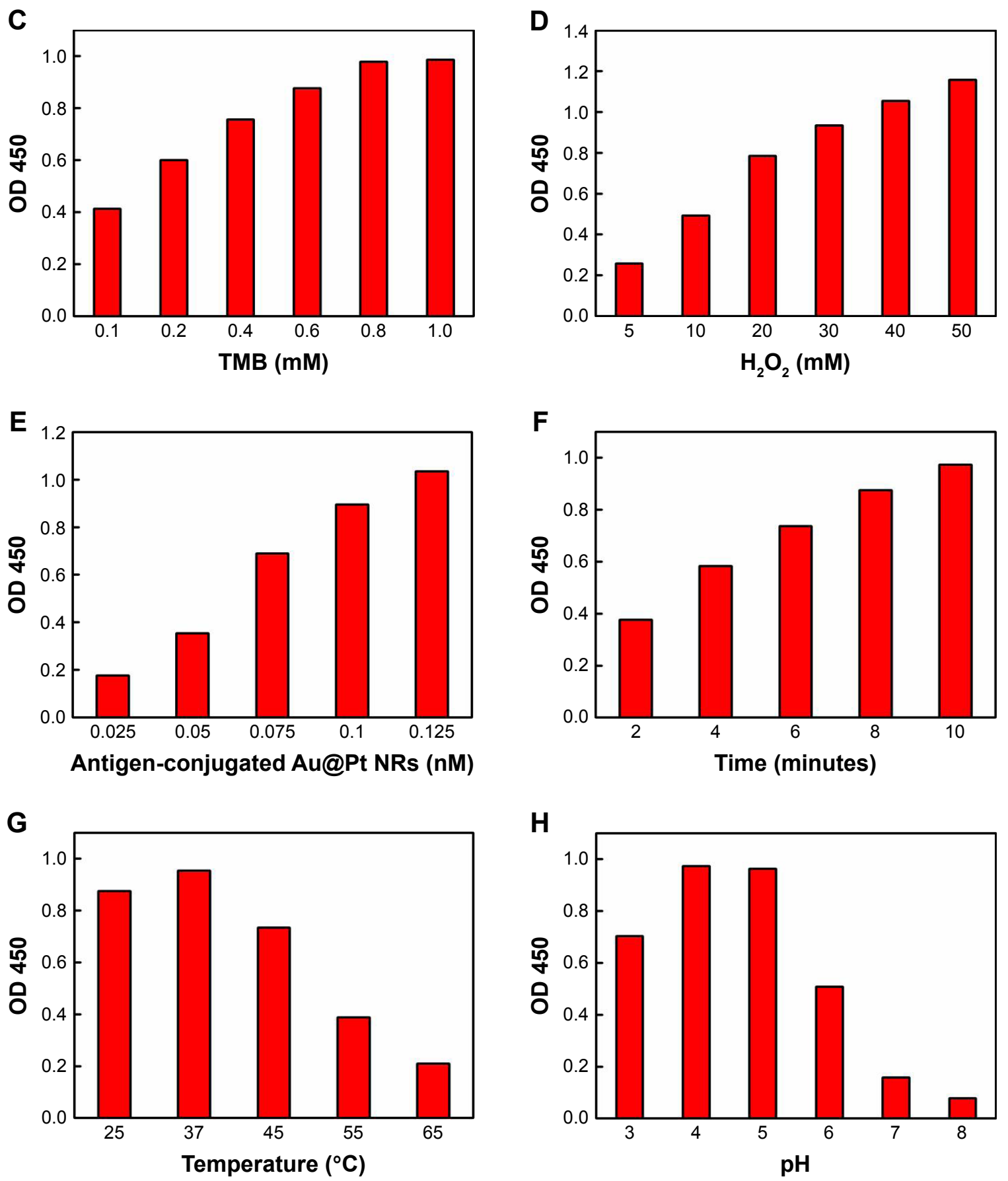

Figure 4 (A) Time-dependent absorbance of TMB oxidation system in the presence of antigen-conjugated Au@Pt NRs. (B) Typical photographs of TMB- $\mathrm{H}_{2} \mathrm{O}_{2}$ solution (left), TMB- $\mathrm{H}_{2} \mathrm{O}_{2}$-antigen-conjugated $\mathrm{Au} @ \mathrm{Pt} \mathrm{NRs}$ (middle), and the reaction solutions after addition of $\mathrm{H}_{2} \mathrm{SO}_{4}$. Effects of $(\mathbf{C})$ TMB concentration, (D) $\mathrm{H}_{2} \mathrm{O}_{2}$ concentration, $(\mathbf{E})$ antigen-conjugated Au@Pt NRs concentration, (F) reaction time, $(\mathbf{G})$ temperature, and $(\mathbf{F})$ pH on the catalytic activity of antigen-conjugated Au@Pt NRs.

Notes: Reaction conditions: (A, B) 0.125 nM antigen-conjugated Au@Pt NRs, I mM TMB, 50 mM H $\mathrm{O}_{2}, 10$ minutes, $37^{\circ} \mathrm{C}$, and 0.1 M, pH 5; (C) 0.125 nM Au@Pt NRs, 50 $\mathrm{mM} \mathrm{H}_{2} \mathrm{O}_{2}, 10$ minutes, $37^{\circ} \mathrm{C}$, and $0.1 \mathrm{M}, \mathrm{pH} 5$; (D) $0.125 \mathrm{nM}$ Au@Pt NRs, I mM TMB, 10 minutes, $37^{\circ} \mathrm{C}$, and $0.1 \mathrm{M}, \mathrm{pH} 5 ;(\mathbf{E}) 1 \mathrm{mM} \mathrm{TMB}, 50 \mathrm{mM} \mathrm{H}_{2} \mathrm{O}_{2}, 10 \mathrm{minutes}, 37^{\circ} \mathrm{C}$, and 0.1 M, pH 5; (F) 0.125 nM Au@Pt NRs, I mM TMB, 50 mM H $\mathrm{O}_{2}, 37^{\circ} \mathrm{C}$, and 0.1 M, pH 5; (G) 0.125 nM Au@Pt NRs, I mM TMB, 50 mM H $\mathrm{O}_{2}$, I0 minutes, and 0.1 M, $\mathrm{pH}$ 5; (H) $0.125 \mathrm{nM}$ Au@Pt NRs, I mM TMB, $50 \mathrm{mM} \mathrm{H} \mathrm{O}_{2}, 10$ minutes, and $37^{\circ} \mathrm{C}$.

Abbreviations: NR, nanorod; TMB, 3,3',5,5'-tetramethylbenzidine.

influence on the performance of the antigen-conjugated Au@, Pt NRs. So, experiments on optimizing $\mathrm{H}_{2} \mathrm{O}_{2}$ concentration were performed and the results are shown in Figure 4D. It reveals that the absorbance at $450 \mathrm{~nm}$ shows an almost linear increase with $\mathrm{H}_{2} \mathrm{O}_{2}$ concentration 5-50 mM. And then, different concentrations of antigen-conjugated Au@Pt NRs were tested with optimum substrate concentration. Figure 4E shows an increase in absorbance with increasing antigen-conjugated Au@Pt NR concentration. The optimized reaction time of antigen-conjugated Au@Pt NRs 
with substrate was also tested for varying time periods (2-10 minutes). Figure 4F shows an increase in absorbance with increasing time of reaction. Finally, the catalytic activity of antigen-conjugated Au@Pt NRs was determined over a range of temperature and $\mathrm{pH}$. The temperature- and $\mathrm{pH}$ dependent response curves are shown in Figure $4 \mathrm{G}$ and $\mathrm{H}$. The phenomenon indicated that the catalytic activity of the antigen-conjugated $\mathrm{Au} @ \mathrm{Pt} \mathrm{NRs}$ in the reaction system of TMB and $\mathrm{H}_{2} \mathrm{O}_{2}$ was strongest at $37^{\circ} \mathrm{C}$ and $\mathrm{pH} 4-5$, which is consistent with the natural enzyme.

To sum up, the optimum conditions selected in the ELISA were as follows: the concentration of TMB was $1 \mathrm{mM}$, the $\mathrm{H}_{2} \mathrm{O}_{2}$ concentration was $50 \mathrm{mM}$, the antigen-conjugated $\mathrm{Au} @$ Pt NRs concentration was 0.125 nM, the reaction time was 10 minutes, the reaction temperature was $37^{\circ} \mathrm{C}$, and the $\mathrm{pH}$ of the reaction buffer was 5 .

\section{Comparison of catalytic stability of antigen-conjugated Au@Pt NRs and antigen-conjugated HRP against temperature and $\mathrm{pH}$}

The stability of enzyme probe under different harsh chemical environments is critical to extend their applications. To examine the relative stabilities of antigen-conjugated $\mathrm{Au} @ \mathrm{Pt} \mathrm{NRs}$ and antigen-conjugated HRP, both of them were pretreated at a range of $\mathrm{pH}$ values (3-9) and temperatures $\left(25^{\circ} \mathrm{C} \sim 85^{\circ} \mathrm{C}\right)$ for 3 hours, and then their peroxidase-like activity was carried out under the standard conditions of $\mathrm{pH} 5.0$ and temperature $37^{\circ} \mathrm{C}$ (Figure 5). Antigen-conjugated Au@Pt NRs showed similar activity over the $\mathrm{pH}$ range studied; however, the reactivity of antigen-conjugated HRP would be affected under acidic conditions (Figure 5A). Figure 5B shows that antigen-conjugated $\mathrm{Au} @$ Pt NRs retained the ability at all temperatures studied after 3 hours pretreatment, while antigen-conjugated HRP lost the majority of its activity above $55^{\circ} \mathrm{C}$. The robustness of antigen-conjugated $\mathrm{Au} @ \mathrm{Pt}$ NRs makes them suitable for a broad range of applications in the biomedicine and environmental chemistry fields under various temperature and $\mathrm{pH}$ conditions.

\section{Application of biomedical assay}

The ELISA kits for the detection of rubella-specific IgM are of the capture type. First, the assay employs anti-human IgM antibody attached to a solid phase. After washing and removal of anti-human $\operatorname{IgM}$ antibody, diluted test serum is added and incubated with the immobilized anti-human $\operatorname{IgM}$ antibody. The rubella-specific IgM antibodies present in the serum bind to anti-human IgM antibody. Then, the unbound antibodies are removed by washing and antigen-conjugated Au NR is added and further incubation is carried out. The quantity of the nanozyme probes that bind to each well is proportional to the concentration of the rubella-specific $\operatorname{IgM}$ antibodies present in the serum. The plates are then washed and substrate is added which results in color development. The enzymatic reaction is stopped after a short incubation period, and OD is measured by an ELISA reader instrument (Figure 1). A dose-response curve drawn for different concentrations of rubella IgM antibodies' standard solutions under optimum
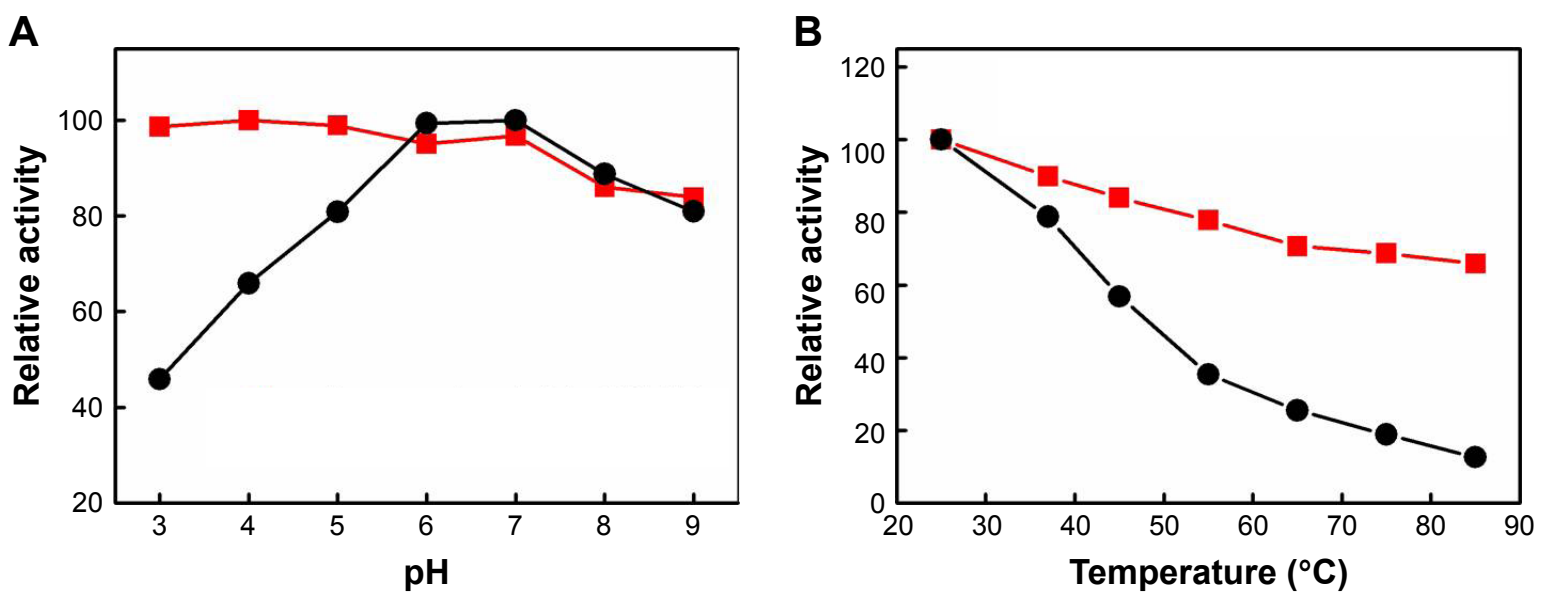

- Antigen-conjugated Au@Pt NRs —- Antigen-conjugated HRP

Figure 5 Comparison of the stability of antigen-conjugated Au@Pt NRs and antigen-conjugated HRP.

Notes: Antigen-conjugated Au@Pt NRs and antigen-conjugated HRP were $(\mathbf{A})$ treated by media with pH ranging from 3 to 9 for 3 hours or (B) treated at a wide range of temperatures between $25^{\circ} \mathrm{C}$ and $85^{\circ} \mathrm{C}$, and then their peroxidase activities were measured under standard conditions.

Abbreviations: HRP, horseradish peroxidase; NR, nanorod. 
A

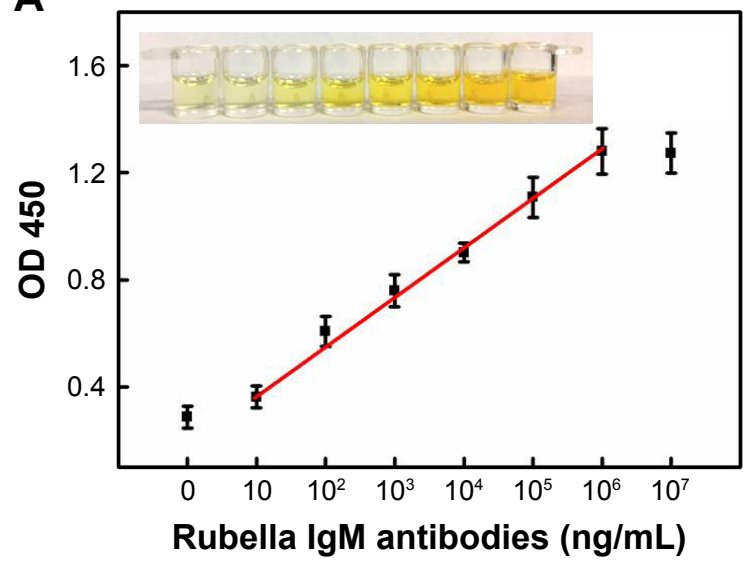

B

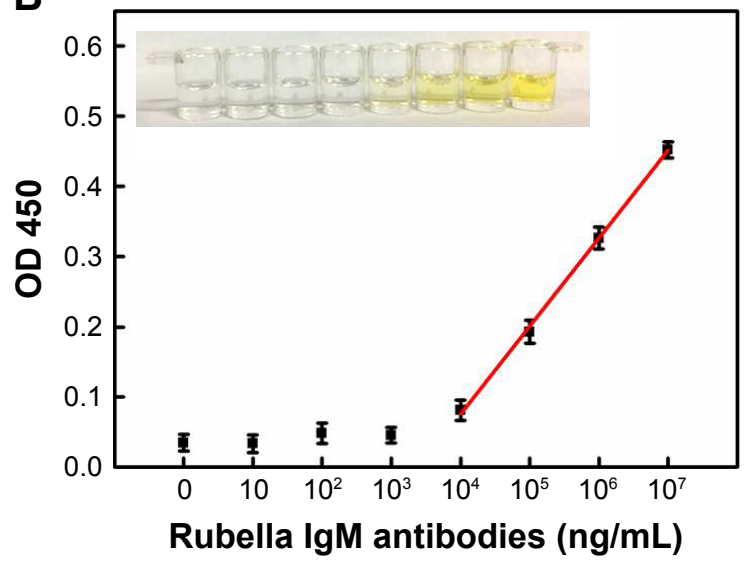

Figure 6 Dose-response curves for different concentrations of rubella IgM antibodies standard solutions.

Notes: (A) Antigen-conjugated Au@Pt NRs-based ELISA and (B) antigen-conjugated HRP-based ELISA. All the error bars were calculated based on the SD of three measurements. The insets are the corresponding colors in the well.

Abbreviations: ELISA, enzyme-linked immunosorbent assay; HRP, horseradish peroxidase; NR, nanorod.

conditions is shown in Figure 6. The detection of rubella IgM antibodies in the linear range from 10 to $10^{6} \mathrm{ng} / \mathrm{mL}$, and the detection limit is as low as $10 \mathrm{ng} / \mathrm{mL}$. Due to the amplified signals generated by the nanoprobes, the detection limit for rubella IgM antibodies increases by three orders of magnitude compared with conventional immunoassays. The increase in sensitivity is attributed to the use of Au@Pt NRs as a carrier and amplifier. First, Au@Pt NRs with high surface areas offer a possibility to load number of antigens to the surface of Au@Pt NRs. More antigens bound onto the Au@Pt NRs surface provide better detection specificity. It, indeed, shows that we can reduce the background signal by harboring more antigens on the particle surface (Figure S3). Second, the largest surface area also provides most catalytic sites, resulting in the strongest peroxidase-like activity compared to that of natural HRP enzyme (Figure S2).

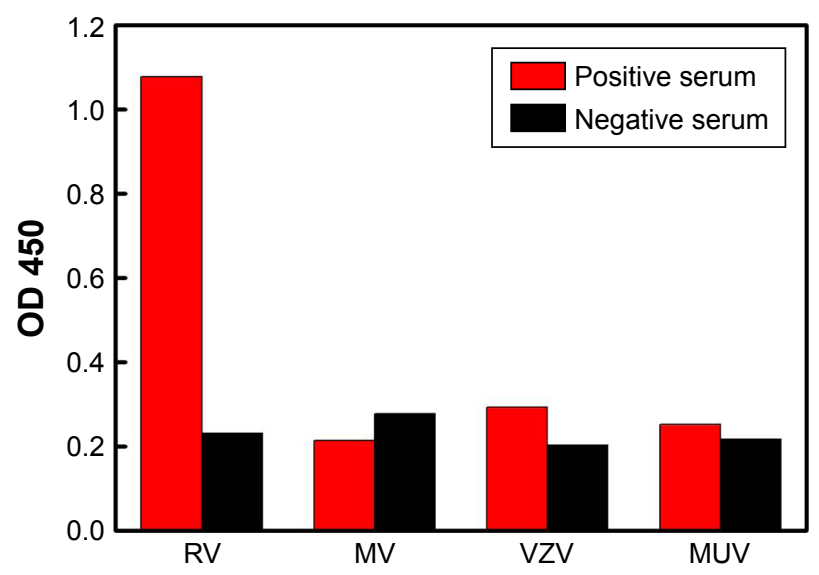

Figure 7 Specificity of antigen-conjugated Au@Pt NRs-based ELISA. Abbreviations: ELISA, enzyme-linked immunosorbent assay; MUV, mumps virus; $\mathrm{MV}$, measles virus; NR, nanorod; VZV, varicella-zoster virus.
Furthermore, it was found that the ELISA system retained nearly the same original optical response (OD 450) even after 4 weeks of storage at $4^{\circ} \mathrm{C}$ (Figure S4), revealing the good stability of the system. Compared to the detection range, the detection time, and the limitations in other rubella IgM immunoassays (Table S1), antigen-conjugated Au@Pt NR is an efficient candidate in the development of rubella IgM immunoassays.

To further investigate the specificity of the ELISA system, the immunoassay was used to detect other infectious viruses, such as measles virus, varicella-zoster virus, and mumps virus. No remarkable response was observed for the other samples in comparison to the result obtained in the RV-positive serum, indicating good specificity of the immunoassay (Figure 7). The proposed method was further validated by testing 30 clinical serum samples with reference to a commercialized ELISA method (20 RV negative and $10 \mathrm{RV}$ positive). When the cutoff value was defined as three times the blank signal, the diagnosis of RV by the antigen-conjugated Au@Pt NRs-based ELISA agreed well with the commercial ELISA result, indicating the proposed immunosensor could be used for the preliminary detection of rubella-specific IgM in clinical diagnosis.

\section{Conclusion}

In this paper, we prepared a novel nanoprobe to detect rubella IgM antibodies in sera. The rationale of detection is based on antigen-conjugated Au@Pt NRs. Compared with HRP-antigen conjugates, the obtained Au@Pt NR-antigen conjugates exhibited not only high peroxidase-like activity, but also robustness to harsh environments. Based on the 
enhanced catalytic properties of this nanozyme probe, the detection limit for rubella-specific IgM antibodies in human serum was as low as $10 \mathrm{ng} / \mathrm{mL}$, which is 1,000 times more sensitive than commercial ELISA. Hence, our experimental results demonstrate the potential feasibility of antibodyconjugated $\mathrm{Au}$ NRs for the highly sensitive virus diagnosis in future clinical applications under various conditions.

\section{Acknowledgments}

This work was financially supported by the National Key Basic Research Program of China (grant nos. 2017YFF0204706 and 2016YFA0200903), the National Natural Science Foundation of China (grant nos. 91127013, 21173056, and 61704149), the Natural Science Foundation of Shandong Province of China (grant no. ZR2017QA004), and the Key Research and Development Program of Shandong Province of China (grant no. 2015GSF118079).

\section{Disclosure}

The authors report no conflicts of interest in this work.

\section{References}

1. Lambert N, Strebel P, Orenstein W, Icenogle J, Poland GA. Rubella. Lancet. 2015;385(9984):2297-2307.

2. Dubois RM, Vaney MC, Tortorici MA, et al. Functional and evolutionary insight from the crystal structure of rubella virus protein E1. Nature. 2013;493(7433):552-556.

3. Bouthry E, Picone O, Hamdi G, Grangeot-Keros L, Ayoubi JM, Vauloup-Fellous C. Rubella and pregnancy: diagnosis, management and outcomes. Prenat Diagn. 2014;34(13):1246-1253.

4. Yolken RH. Enzyme-linked immunosorbent assay (ELISA): a practical tool for rapid diagnosis of viruses and other infectious agents. Yale $J$ Biol Med. 1980;53(1):85-92.

5. Saijo M, Niikura M, Morikawa S, et al. Enzyme-linked immunosorbent assays for detection of antibodies to Ebola and Marburg viruses using recombinant nucleoproteins. J Clin Microbiol. 2001;39(1):1-7.

6. Wright PF, Nilsson E, van Rooij EM, Lelenta M, Jeggo MH. Standardisation and validation of enzyme-linked immunosorbent assay techniques for the detection of antibody in infectious disease diagnosis. Rev Sci Tech. 1993;12(2):435-450.

7. Helfand RF, Cabezas C, Abernathy E, et al. Dried blood spots versus sera for detection of rubella virus-specific immunoglobulin M (IgM) and $\mathrm{IgG}$ in samples collected during a rubella outbreak in Peru. Clin Vaccine Immunol. 2007;14(11):1522-1525.

8. Helfand RF, Keyserling HL, Williams I, et al. Comparative detection of measles and rubella IgM and IgG derived from filter paper blood and serum samples. J Med Virol. 2001;65(4):751-757.

9. Raynal M, Ballester P, Vidal-Ferran A, van Leeuwen PW, van P. Supramolecular catalysis. Part 2: artificial enzyme mimics. Chem Soc Rev. 2014;43(5):1734-1787.

10. Nanda V, Koder RL. Designing artificial enzymes by intuition and computation. Nat Chem. 2010;2(1):15-24.

11. Murakami Y, Kikuchi Ji J-Ichi, Hisaeda Y, Hayashida O. Artificial Enzymes. Chem Rev. 1996;96(2):721-758.

12. Breslow R. Biomimetic Chemistry and Artificial Enzymes: Catalysis by Design. Accounts of Chemical Research. 1995;28(3):146-153.

13. Gao L, Zhuang J, Nie L, et al. Intrinsic peroxidase-like activity of ferromagnetic nanoparticles. Nat Nanotechnol. 2007;2(9):577-583.
14. Lin Y, Ren J, Qu X. Catalytically active nanomaterials: a promising candidate for artificial enzymes. Acc Chem Res. 2014;47(4):1097-1105.

15. Wei H, Wang E. Nanomaterials with enzyme-like characteristics (nanozymes): next-generation artificial enzymes. Chem Soc Rev. 2013; 42(14):6060-6093.

16. Hu X, Liu J, Hou S, et al. Research progress of nanoparticles as enzyme mimetics. Science China Physics, Mechanics and Astronomy. 2011;54(10):1749-1756.

17. Natalio F, André R, Hartog AF, et al. Vanadium pentoxide nanoparticles mimic vanadium haloperoxidases and thwart biofilm formation. Nat Nanotechnol. 2012;7(8):530-535.

18. Kim CK, Kim T, Choi IY, et al. Ceria nanoparticles that can protect against ischemic stroke. Angew Chem Int Ed Engl. 2012;51(44): 11039-11043.

19. Wan Y, Qi P, Zhang D, Wu J, Wang Y. Manganese oxide nanowiremediated enzyme-linked immunosorbent assay. Biosens Bioelectron. 2012;33(1):69-74.

20. Lin Y, Ren J, Qu X. Nano-gold as artificial enzymes: hidden talents. Adv Mater. 2014;26(25):4200-4217.

21. Fan J, Yin JJ, Ning B, et al. Direct evidence for catalase and peroxidase activities of ferritin-platinum nanoparticles. Biomaterials. 2011; 32(6):1611-1618.

22. Ge C, Fang G, Shen X, et al. Facet Energy versus Enzyme-like Activities: The Unexpected Protection of Palladium Nanocrystals against Oxidative Damage. ACS Nano. 2016;10(11):10436-10445.

23. Han L, Li C, Zhang T, Lang Q, Liu A. Au@Ag Heterogeneous Nanorods as Nanozyme Interfaces with Peroxidase-Like Activity and Their Application for One-Pot Analysis of Glucose at Nearly Neutral pH. ACS Appl Mater Interfaces. 2015;7(26):14463-14470.

24. Song Y, Wang X, Zhao C, Qu K, Ren J, Qu X. Label-free colorimetric detection of single nucleotide polymorphism by using single-walled carbon nanotube intrinsic peroxidase-like activity. Chemistry. 2010; 16(12):3617-3621.

25. Song Y, Qu K, Zhao C, Ren J, Qu X. Graphene oxide: intrinsic peroxidase catalytic activity and its application to glucose detection. Adv Mater. 2010;22(19):2206-2210.

26. He W, Jia $\mathrm{H}, \mathrm{Li}$ X, et al. Understanding the formation of $\mathrm{CuS}$ concave superstructures with peroxidase-like activity. Nanoscale. 2012;4(11): 3501-3506.

27. Wang X, Hu Y, Wei H. Nanozymes in bionanotechnology: from sensing to therapeutics and beyond. Inorg Chem Front. 2016;3(1):41-60.

28. Zhou Y, Liu B, Yang R, Liu J. Filling in the Gaps between Nanozymes and Enzymes: Challenges and Opportunities. Bioconjug Chem. 2017;28(12):2903-2909.

29. Gao L, Yan X. Nanozymes: an emerging field bridging nanotechnology and biology. Sci China Life Sci. 2016;59(4):400-402.

30. Kuah E, Toh S, Yee J, Ma Q, Gao Z. Enzyme Mimics: Advances and Applications. Chemistry. 2016;22(25):8404-8430.

31. Ragg R, Tahir MN, Tremel W. Solids Go Bio: Inorganic Nanoparticles as Enzyme Mimics. Eur J Inorg Chem. 2016;2016(13-14):1906-1915.

32. Cormode DP, Gao L, Koo H. Emerging Biomedical Applications of Enzyme-Like Catalytic Nanomaterials. Trends Biotechnol. 2018; 36(1):15-29.

33. He W, Liu Y, Yuan J, et al. Au@Pt nanostructures as oxidase and peroxidase mimetics for use in immunoassays. Biomaterials. 2011;32(4): 1139-1147.

34. Liu J, Hu X, Hou S, et al. Screening of inhibitors for oxidase mimics of Au@Pt nanorods by catalytic oxidation of OPD. Chem Commun. 2011; 47(39):10981-10983.

35. Liu J, Hu X, Hou S, et al. Au@Pt core/shell nanorods with peroxidaseand ascorbate oxidase-like activities for improved detection of glucose. Sens Actuators B Chem. 2012;166-167(6):708-714.

36. Liu J, Jiang X, Wang L, et al. Ferroxidase-like activity of Au nanorod/ Pt nanodot structures and implications for cellular oxidative stress. Nano Res. 2015;8(12):4024-4037.

37. Zhou Y-T, He W, Wamer WG, et al. Enzyme-mimetic effects of gold@platinum nanorods on the antioxidant activity of ascorbic acid. Nanoscale. 2013;5(4):1583-1591. 


\section{Supplementary materials}

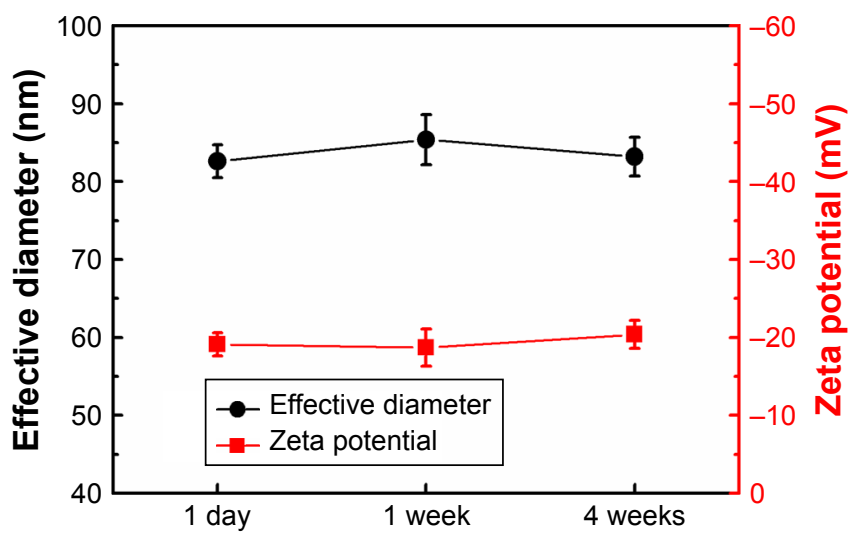

Figure SI Effects of storage time on the stability of antigen-conjugated Au NRs in 0.I M PBS solution ( $\mathrm{pH}=7.4)$ at room temperature. Note: All the error bars were calculated based on the SD of three measurements.

Abbreviation: NR, nanorod.

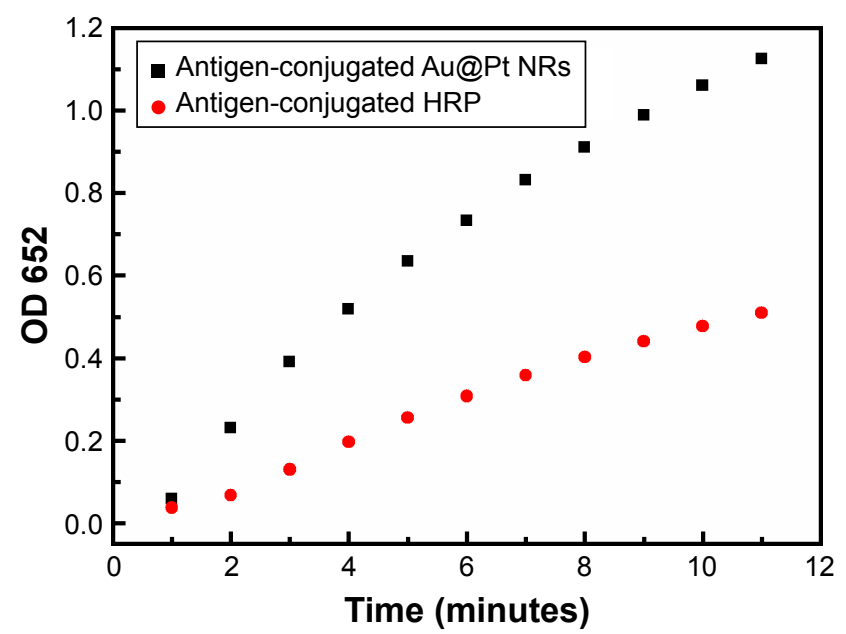

Figure S2 The absorbance evolution at $650 \mathrm{~nm}$ over time for TMB oxidation catalyzed by antigen-conjugated Au@Pt NRs and antigen-conjugated HRP. Note: Reaction conditions: I mM TMB, $50 \mathrm{mM} \mathrm{H}_{2} \mathrm{O}_{2}, 10$ minutes, $37^{\circ} \mathrm{C}$, and $0.1 \mathrm{M}$, pH 5 .

Abbreviations: HRP, horseradish peroxidase; NR, nanorod; TMB, 3,3',5,5'-tetramethylbenzidine.

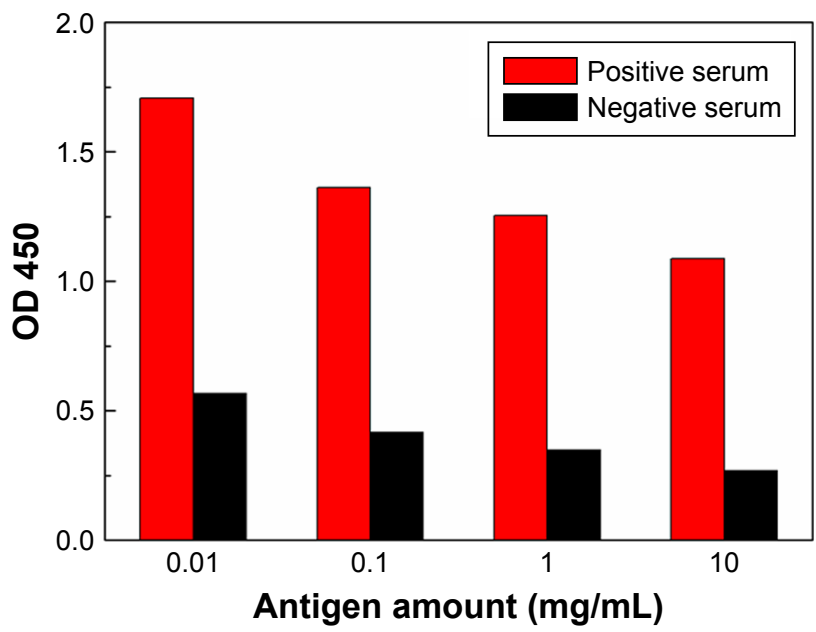

Figure S3 Effects of the amount of antigens on Au@Pt NR surface for the performance of the immunoassay.

Note: The resulting antigen-conjugated Au@Pt NRs were evaluated by detecting positive control and negative control.

Abbreviation: NR, nanorod. 


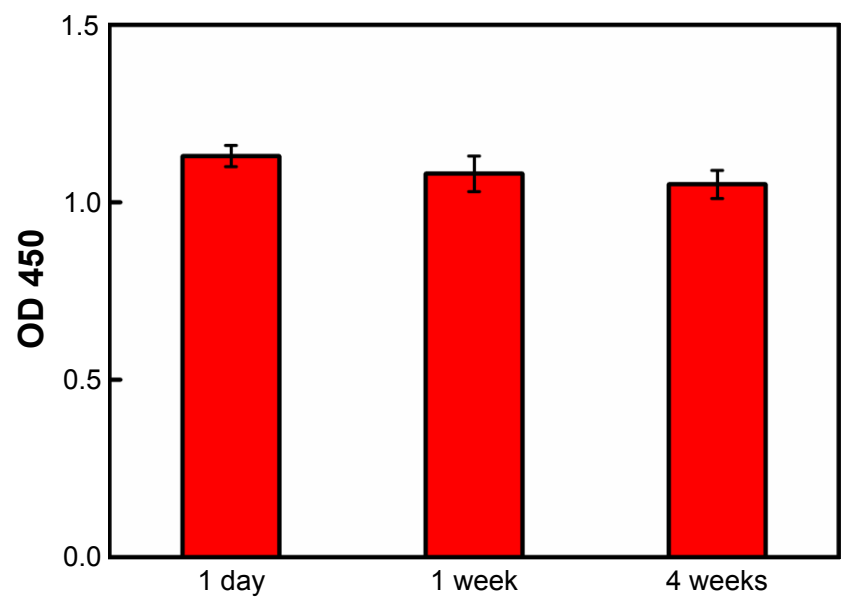

Figure S4 Effects of storage time on the reactivity of antigen-conjugated Au@Pt NRs in 0.I M PBS solution ( $\mathrm{pH}=7.4)$ at room temperature.

Notes: All the error bars were calculated based on the SD of three measurements. Reaction conditions: $0.125 \mathrm{nM}$ antigen-conjugated Au@Pt NRs, I mM TMB, $50 \mathrm{mM}$ $\mathrm{H}_{2} \mathrm{O}_{2}, 10$ minutes, $37^{\circ} \mathrm{C}$, and $0.1 \mathrm{M}, \mathrm{pH} 5$.

Abbreviations: NR, nanorod; TMB, 3,3',5,5'-tetramethylbenzidine.

Table SI Comparison of rubella IgM immunoassay

\begin{tabular}{|c|c|c|c|c|}
\hline System & Detection method & $\begin{array}{l}\text { Detection } \\
\text { range }(\mathrm{ng} / \mathrm{mL})\end{array}$ & $\begin{array}{l}\text { Detection } \\
\text { time (hours) }\end{array}$ & Limitations \\
\hline $\begin{array}{l}\text { Sigma rubella IgM (capture) (Sigma-Aldrich } \\
\text { Co., St Louis, MO, USA) }\end{array}$ & IgM capture format assay & $10^{3}-10^{7}$ & $\sim 2.5$ & Relative low stability \\
\hline Sigma rubella IgM (Sigma-Aldrich Co.) & Indirect format assay & $10^{3}-10^{7}$ & $\sim 1.5$ & Gives false-positive results \\
\hline This work & IgM capture format assay & $10-10^{7}$ & $\sim 2$ & $\begin{array}{l}\text { No commercial assay } \\
\text { available }\end{array}$ \\
\hline
\end{tabular}

International Journal of Nanomedicine

\section{Publish your work in this journal}

The International Journal of Nanomedicine is an international, peerreviewed journal focusing on the application of nanotechnology in diagnostics, therapeutics, and drug delivery systems throughou the biomedical field. This journal is indexed on PubMed Central, MedLine, CAS, SciSearch $®$, Current Contents $\AA /$ Clinical Medicine,
Journal Citation Reports/Science Edition, EMBase, Scopus and the Elsevier Bibliographic databases. The manuscript management system is completely online and includes a very quick and fair peer-review system, which is all easy to use. Visit http://www.dovepress.com/ testimonials.php to read real quotes from published authors.

\footnotetext{
Submit your manuscript here: http://www.dovepress.com/international-journal-of-nanomedicine-journal
} 